\title{
Protein S Deficiency and Pulmonary Embolism in Children: A Case Report and Review of Literature
}

ISSN: 2576-9200

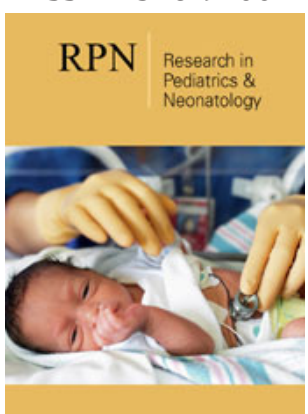

*Corresponding author: Othman Rizk A Mishref, Pediatrics \& Neonatology Department, Kuwait Hospital, Kuwait

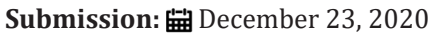

Published: : March 04, 2021

Volume 5 - Issue 3

How to cite this article: Othman Rizk A Mishref, Abdelrahman A Beridan, Amr Abdelmordy E Samaka. Protein S Deficiency and Pulmonary Embolism in Children: A Case Report and Review of Literature. Research in Pediatrics \& Neonatology. 5(3). RPN. 000614. 2021. DOI: $10.31031 /$ RPN.2021.05.000614

Copyright(c) Othman Rizk A Mishref. This article is distributed under the terms of the Creative Commons Attribution 4.0 International License, which permits unrestricted use and redistribution provided that the original author and source are credited.

\author{
Othman Rizk A Mishref*1, Abdelrahman A Beridan² and Amr Abdelmordy E \\ Samaka $^{2}$ \\ ${ }^{1}$ Pediatrics \& Neonatology Department, Kuwait Hospital, Kuwait \\ ${ }^{2}$ Cardiology Department, Wara Hospital, Kuwait
}

\begin{abstract}
Protein S deficiency is a major risk factor for venous thromboembolism. Unprovoked life-threatening pulmonary embolism is uncommon in children; however, it can pose a diagnostic challenge, presenting in a non-specific and subtle way, masked by lack of typical presentation. Therefore, it is important for pediatrician to consider pulmonary embolism as a differential diagnosis for young patients presenting with severe unexplained parasternal chest pain with strong family history of thrombophilia and to have a low threshold for requesting appropriate investigations. Here we present a young patient with acute pulmonary embolism who was finally diagnosed as Type III Protein S deficiency.
\end{abstract}

Keywords: Protein S deficiency; Pulmonary Embolism; Venous Thromboembolism; Thrombosis

\section{Case Presentation}

A previously healthy 12-year-old boy presented overnight to the accident and emergency unit with dull aching left parasternal chest pain. The patient denied any history of trauma, heavy muscular exercise, fever, chocking, cough, respiratory infection, drug intake, gastroesophageal reflux disease, cardiac problems, or skin rash. His vital signs were normal, oxygen saturation was $96 \%$ on room air, unremarkable systemic examination and chest $\mathrm{x}$-ray was normal. This patient is obese, his height is $155 \mathrm{~cm}$ ( $>75^{\text {th }}$ percentile), weight is $70 \mathrm{~kg}$ ( $>95^{\text {th }}$ percentile) and BMI is 28.2. He was given nonsteroidal analgesic and sent home. Unfortunately, one hour later, the patient came back with severe agonizing left parasternal chest pain associated with difficult breathing in the form of tachypnea (respiratory rate, $32 / \mathrm{m}$ ) and intercostal retraction, tachycardia (heart rate, $120 \mathrm{~b} / \mathrm{m}$ ), Blood pressure $100 / 60 \mathrm{mmHg}$. Spo 2 was $88 \%$ in air, high-flow Oxygen 10L/m was applied by high flow mask, Spo2 improved to $98 \%$, and an arterial blood gas showed an evidence of type 1 respiratory failure $\left(\mathrm{pH} 7.43, \mathrm{pO}_{2} 56 \mathrm{mmHg}\right.$, $\mathrm{pCO}_{2} 30 \mathrm{mmHg}$, $\mathrm{Hco} 3$ 18.2).

ECG showed sinus tachycardia, evidence of right ventricular strain and suspected pulmonary embolism in the form of $S_{I}, Q_{I I I}, T_{\text {III }}$ (deep S wave in lead I, Q wave and inverted T wave in lead III). The patient was given morphine $5 \mathrm{mg} / \mathrm{kg}$ intramuscular. Urgent Echocardiography was done and revealed mild tricuspid regurgitation. An urgent CT pulmonary angiogram was requested and showed an evidence of sub-massive pulmonary embolism. The legs were free of edema and there was no calf tenderness or erythema. Otherwise, systemic examination was unremarkable. He had no previous thrombotic events. No past medical history of Neurological disorder, stroke, slurring of speech, headache, blurring of vision, or loss of consciousness or seizures. No history of gout, hypertension, diabetes mellitus, dyslipidemia, smoking or chronic kidney disease. Tracing the family history, his uncle died suddenly at the age of 20 years old without any obvious cause and there is a history of hypercoagulability and venous thromboembolic disease in the other branch of the family of the father, but he does not know the exact cause, this information was missed initially by the father because of his anxiety. 
Initial blood work on presentation showed a WBCs $11.3 \times 10^{3} /$ uL hemoglobin of 15g/dL (normal range: 13.5-17.5), HCT $44.6 \%$, platelets $268 \times 10^{3} / \mathrm{uL}$ (normal range: 140-440), reticulocyte count $1.8 \%$ (normal range: 0.5-2), Coagulation profile (APTT: $33.2 \mathrm{sec}$, PT: $15.3 \mathrm{sec}$, Pc $84.9 \%$, INR: 1.17 , fibrinogen was $5.25 \mathrm{~g} / \mathrm{L}$, lactate dehydrogenase 213U/L (normal range: 140-271), Peripheral blood film was negative for schistocytes, and haptoglobin 132mg/ dL (normal range: 34-200mg/dL). COVID-19: Negative, CK-MB: 1.0 (N. 0.00- 4.3ng/mL), Troponin: 0.85 (N. 0.00- 0.40ng/mL) Electrolytes, glucose, calcium, phosphorus, blood urea nitrogen (BUN), creatinine, Liver Function Tests and lipid profile all were normal. Urine analysis and microscopy were normal and there were no red blood cells. A thrombophilia screening profile of this patient identified protein S deficiency (free protein S activity: $23 \%$, and normal total protein $\mathrm{S}$ level). The activity of protein $\mathrm{C}$ and antithrombin III was within the normal limits $(80 \%$ and $111 \%$, respectively). Other results, including levels of homocysteine, factor II Prothrombin mutation G20210, factor V Leiden G1691A, anti-cardiolipin antibody, and anti- $\beta 2$-glycoprotein IgM and IgG, all were negative. Therefore, a diagnosis of type III protein $\mathrm{S}$ deficiency (low free protein S activity and normal total protein S level) was established.

CT angiography showed picture suggestive of sub-massive acute pulmonary embolism including segmental and sub-segmental branches of both pulmonary arteries bilaterally (right more than left). There is patchy consolidation of the basal segment of the left lung with mild left pleural effusion. Furthermore, Leg veins color Doppler ultrasound was done and demonstrated no evidence of Deep Venous Thrombosis; moreover, in addition to, non-contrast Brain CT showed no acute abnormalities. The patient's father had been thrombosis-free, but he was also found to have PS deficiency with low PS activity (25\%). No additional abnormalities were found in any of the subjects after testing for anticardiolipin antibodies, protein C level and activity, APCR-assay, factor V Leiden, and prothrombin G20210A.

Coagulation profile was repeated after starting therapy (APTT: $35 \mathrm{sec}$, PT: 14.5 sec, Pc: 96.3\%, INR: 1.2

Repeat WBCs 7.9 x 103/uL hemoglobin of 13.7g/dL (normal range: 13.5-17.5), HCT $42 \%$, platelets $314 \times 103 / \mathrm{uL}$ (normal range: 140-440), lactate dehydrogenase 213U/L (normal range: 140-271), Peripheral blood film was negative for schistocytes, and haptoglobin $152 \mathrm{mg} / \mathrm{dL}$ (normal range: 34-200).

\section{Differential Diagnosis}

Due to the degree of hypoxia, family history of thrombophilia and right heart strain, massive pulmonary embolism remained the most likely diagnosis that was confirmed with High resolution CT pulmonary angiography chest Table 1 . Other differentials were also considered, such as community-acquired pneumonia with pleurisy due to hypoxia and chest pain, but this did not explain the significant chest pain and the patient did not have fever, productive cough or patchy shadowing on chest x-ray. A patient presenting with shortness of breath and low oxygen saturations raises the possibility of a pneumothorax, but clinical examination and chest x-ray did not correlate with this diagnosis. Importantly, cardiac causes such as an inherited cardiomyopathy or connective tissue disease causing acute valvular pathology or dissection should remain a high differential diagnosis but ECG, Echocardiography, and CT pulmonary angiography excluded cardiac causes. Thrombophilia profile confirmed diagnosis of acute pulmonary embolism with Type III Protein S deficiency.

Table 1.

\begin{tabular}{|c|c|c|}
\hline \multicolumn{3}{|c|}{ Thrombophilia Screening Profile } \\
\hline - Protein C: & $80 \mathrm{IU} / \mathrm{dL}$ & (N. 65-13 IU/dL) \\
\hline - Protein $\mathrm{C}$ activity: & $80 \%$ & $70-140 \%$ \\
\hline - Total Protein S: & $18 \mathrm{U} / \mathrm{dL}$ & (N. 15-35U/dL) \\
\hline - Protein S Free Antigen Assay: & $23 \%$ & (N. 67-138\%) \\
\hline - D-Dimer: & $127 \mathrm{ng} / \mathrm{mL}$ & $(\mathrm{N} .<500 \mathrm{ng} / \mathrm{mL})$ \\
\hline - Factor II Prothrombin mutation by PCR: & Negative G20210A allele & Negative G20210A allele \\
\hline - Antithrombin III activity: & $111 \%$ & (N. 79-131\%) \\
\hline - Factor V Activity: & $251.70 \%$ & $(\mathrm{~N} .>120 \%)$ \\
\hline - Factor Xa activity: & $115 \%$ & $50-150 \%$ \\
\hline - Activated Protein C resistance (APCR) assay: & 2.59 & (Normal: > 2.4, Resistance: $\leq 2.4$ ) \\
\hline - Anti-Beta 2 Glycoprotein Antibodies IgG: & $3.2 \mathrm{U} / \mathrm{ml}$ & $\begin{array}{c}\text { (Negative: }<5.0 \text {, Borderline: } 5.0-8.0 \text {, positive: } \\
\qquad>8.0 \mathrm{U} / \mathrm{ml} \text { ) }\end{array}$ \\
\hline - Anti-Beta 2 Glycoprotein Antibodies IgM: & $1 \mathrm{U} / \mathrm{ml}$ & $\begin{array}{c}\text { (Negative: < 5.0, Borderline: } 5.0-8.0 \text {, positive: } \\
\qquad>8.0 \mathrm{U} / \mathrm{ml} \text { ) }\end{array}$ \\
\hline - Anti-cardiolipin IgG: & 1.9 GPL-U/ML & (Negative $<10.0$, Positive $\geq 10.0$ MPL-U/ML) \\
\hline
\end{tabular}




\begin{tabular}{|c|c|c|}
\hline$\cdot$ Anti-cardiolipin IgM: & $1.2 \mathrm{MPL}-\mathrm{U} / \mathrm{ML}$ & (Negative $<7.0$, Positive $\geq 7.0 \mathrm{MPL}-\mathrm{U} / \mathrm{ML}$ ) \\
\hline$\bullet$ Lupus anticoagulant: & 43.1 & $(\mathrm{~N} .34-54)$ \\
\hline$\cdot$ Homocysteine & $12 \mu \mathrm{mol} / \mathrm{L}$ & $<16 \mu \mathrm{mol} / \mathrm{L}$ \\
\hline$\cdot$ ADAMTS 13 activity & $80 \%$ & $(\mathrm{~N} .50-160 \%)$ \\
\hline
\end{tabular}

\section{Treatment and Outcome}

His symptoms and signs subsided after treatment with Enoxaparin $1 \mathrm{mg} / \mathrm{kg} /$ dose, every 12 hours and then maintenance $1 \mathrm{mg} / \mathrm{kg}$ once daily. He has also been offered genetic counselling advice in the future, should he wish to start a family. Hematology consultation was done and planned for follow up and genetic counselling for the family.

\section{Background}

Pulmonary embolism is defined as a blockage of a pulmonary artery or one of its vessels by thrombus, fat, amniotic fluid or air. A massive pulmonary embolism is characterized by hypotension, shock, right ventricular dysfunction and/or myocardial injury [1]. Venous thromboembolism (VTE) in a young, healthy patient is uncommon in the absence of a provoking factor. VTE occurs when $\geq 1$ component of Virchow's triad is activated: stasis of blood flow, injury to the endothelial lining, and hypercoagulability of blood components. This is the most useful pathophysiological construct for thinking about thromboembolism in children [2]. Protein S (PS) deficiency contributes to $2 \%$ of all venous thromboembolisms presenting to accident and emergency and its deficiency is a major risk factor for venous thrombosis [3]. Studies of families with thrombophilia revealed that individuals with PS deficiency have a five to ten-folds higher risk for VTE than healthy relatives [4].

PS, a vitamin K-dependent glycoprotein, circulates in plasma in two forms: a complex with C4b-binding protein (bound form $60 \%$ of total PS) and, in part as the functionally active form "free" protein S (40 \%) [5]. PS, mainly synthesized in the liver and endothelial cells, is a cofactor of activated protein C (PC). The free form serves as cofactor with APC to inactivates factor FVa and FVIIIa, thereby restricting thrombin generation. Furthermore, the anticoagulant activity of PS might act independently from PC via an additional non-enzymatic cofactor function for tissue factor pathway inhibitor thereby promoting inhibition of FXa. Additionally, PS plays a direct role in inhibition of thrombin generation via inhibition of FXa and FVa in the prothrombinase complex [6].

PS deficiency is detected using tests for PS antigen (total antigen or free PS antigen). Decreased levels of PS are found in inherited deficiency of PS as well as in some acquired conditions, such as liver diseases, vitamin $\mathrm{K}$ deficiency, therapy with vitamin $\mathrm{K}$ antagonists, pregnancy, HIV infection, varicella, sickle cell disease, malignancy, and nephrotic syndrome [7].

Protein S deficiency (PSD) usually presents as heterozygous deficiency and segregates as an autosomal dominant trait.
Heterozygous carriers may manifest at a later age; meanwhile, homozygous PSD can lead to an early thrombotic onset in the neonatal or infant period. According to plasma levels of total PS, free PS antigen and PS activity, PS deficiency is classified into 3 types; Type I is a quantitative deficiency in the total PS and free PS. Type II (qualitative PS deficiency) is characterized by normal PS levels but reduced PS activity due to a dysfunctional PS variant in plasma. Type III PS deficiency is characterized by low levels of free PS, though the total plasma concentration of PS is normal [8].

The inherited PS deficiency is an autosomal dominant condition. Molecular studies identified two genes encoding PS, linked closely on chromosome 3p11.1-3q11.2: the active gene, PROS-b (PROS1) and the other, the pseudogene PROS-a, a nonfunctional gene, similar with the active gene, but without the exon 1 . Almost 200 mutations of PROS1 gene have been described, such as: the PS Heerlen mutation (due to the substitution of Ser 460 by Pro, consecutive to $\mathrm{T} / \mathrm{C}$ transition in exon 13 ) resulting in type III deficiency, the PS Tokushima due to K196E substitution, located in the epidermal growth factor-2 domain and causing type II deficiency [3]. LMWH has become the anticoagulant of choice in many pediatric patients for a variety of reasons. The most reported LMWH used in pediatric patients is enoxaparin. LMWH may require weekly monitoring of anti-Xa levels in children in the inpatient setting requiring therapeutic Xa levels. In asymptomatic individuals with PS deficiency, the prophylaxis of VTE should be done in the presence of a major acquired risk factor for thrombosis [9].

\section{Discussion}

Unprovoked life-threatening pulmonary embolism is uncommon in children. They can pose a diagnostic challenge, presenting in a non-specific and subtle way, masked by lack of typical presentation. Interestingly, in the case described above, the patient presented with pulmonary embolism without any other acquired risk factors, indicating a potential abnormality in anticoagulation mechanisms. In our opinion, children presented with pulmonary embolism in the absence of precipitating factors need to be tested to identify whether there is a deficiency of PC, PS, or antithrombin III (AT III). In this case, the patient was found to be PS deficient.

Current evidence indicates that screening for inherited thrombophilia is appropriate in cases of VTE without obvious cause for VTE in patients with a positive family history of thrombosis; recurrent VTE; thrombosis at an unusual location; and developing VTE during pregnancy, use of oral contraceptives, or hormone replacement therapy [10]. Therefore, it is important for pediatrician 
to consider pulmonary embolism as a differential diagnosis for young patients and have a low threshold for requesting appropriate investigations. Virchow's triad describes three primary causes of venous and arterial thrombosis: abnormalities in the circulating blood, stasis and injury to the vessel wall [11]. Hereditary thrombophilias are associated with blood abnormalities and are characterized by venous thromboembolic events at a young age. These are often unprovoked and recurrent, occurring at unusual locations and associated with a family history. Protein S deficiency predisposes to higher risk of venous thromboembolism than the general population with normal protein S level [12].

Obtaining a thorough family history on admission is very crucial to aid diagnosis. The patient presented with significant hypoxia and right ventricular strain suspicious of pulmonary embolism. An urgent CT pulmonary angiogram, the main investigative modality on admission, was requested and revealed the life-threatening extent of pulmonary embolism, allowing immediate treatment. As this was the case with our patient, having a family history of thrombophilia prompted to investigate for hereditary thrombophilia including protein S deficiency. In patients with a coexisting clinical deep vein thrombosis, leg color Doppler ultrasound as the initial imaging test can be sufficient to confirm venous thromboembolism [13]. But this was not there in our case. To prove inherited deficiency, testing of family members is recommended. Both patient and family members should receive genetic counseling prior to genetic testing, and such testing should only be performed after obtaining consent. Interestingly, the patient's father had also PS deficiency, but was thrombosis-free, suggesting that a triggering event might have been involved in the patient's thrombus formation or the existence of a protective mechanism in the patient's father.

\section{Summary}

In summary, our report supports the view that PS deficiency should be taken into consideration for children with pulmonary embolism presenting with unexplained chest pain without obvious predisposing factors. Family history is extremely important in such cases and genetic studies could be valuable in the identification of PROS1 mutations for the PS deficient patients. Following the confirmation of massive pulmonary embolism, the patient received enoxaparin and genetic testing for the family is requested.

\section{Learning Points}

A. Protein S deficiency is a rare but important cause for venous thromboembolism in children.

B. A thorough family history should be incorporated into the medical clerking of all patients admitted to the accident and emergency.
C. Knowledge of the presence of hereditary illnesses, such as thrombophilia, provides a very significant guidance in creating differential diagnoses, prioritizing investigations and providing the best care for the patient.

D. Pulmonary emboli can present with non-specific symptoms. Meticulous clinical assessment of the patient as well as a low threshold for investigation on admission can be lifesaving.

E. children presenting with unprovoked pulmonary emboli, clinicians should consider inherited prothrombotic factors as a potential cause. A thrombophilia screen not only allows for better management of the patient, but also enables diagnosis of family members.

F. DNA-based testing is a useful diagnostic approach to diagnose protein $\mathrm{S}$ deficiency when more than one family member is affected with thrombosis.

\section{References}

1. Torbicki A, Perrier A, Konstantinides S, Agnelli G, Galie N, et al. (2008) Guidelines on the diagnosis and management of pulmonary embolism: The task force for the diagnosis and management of acute pulmonary embolism of the European society of cardiology(ESC). Eur Heart J 29(18): 2276-315.

2. Witmer CM, Takemoto CM (2017) Pediatric hospital acquired venous thromboembolism. Front Pediatr 5: 198.

3. Ten Kate MK, Der Meer JV (2008) Protein S deficiency: A clinical perspective. Haemophilia 14(6): 1222-1228.

4. Yin T, Miyata T (2009) Venous thromboembolic risk and protein S deficiency: Ethnic difference and remaining issues J Geriatr Cardiol 6(1): 11-19.

5. Dahlbäck B (2007) The tale of protein $S$ and $C_{4}$ b-binding protein, a story of affection. Thromb Haemost 98(1): 90-96.

6. Castoldi E, Simioni P, Tormene D, Rosing J, Hackeng TM (2010) Hereditary and acquired protein $S$ deficiencies are associated with low TFPI levels in plasma. J Thromb Haemost 8(2): 294-300.

7. Matthes BK (1992) Acquired protein S deficiency. Clin Investig 70(6): 529-534.

8. Martinelli I, Bucciarelli P, Artoni A, Fossali EF, Passamonti SM (2013) Anticoagulant treatment with rivaroxaban in severe protein $S$ deficiency. Paediatrics 132(5): e1435-1439.

9. Monagle $\mathrm{P}$, Chan AKC, Goldenberg NA, Ichord RN, Journeycake JM, et al. (2012) Antithrombotic therapy in neonates and children: Antithrombotic therapy and prevention of thrombosis, $9^{\text {th }}$ ed: American college of chest physicians evidence-based clinical practice guidelines. Chest 141(2 suppl): e737S-e801S.

10. Wypasek E, Undas A (2013) Protein C and protein S deficiency: Practical diagnostic issues. Adv Clin Exp Med 22(4): 459-67.

11. Khan S, Dickerman JD (2006) Hereditary thrombophilia. Thromb J 4: 15.

12. Dykes AC, Walker ID, McMahon AD, Islam SI, Tait RC (2001) A study of protein $S$ antigen levels in 3788 healthy volunteers: Influence of age, sex and hormone use, and estimate for prevalence of deficiency state. Br J Haematol 113(3): 636-634.

13. British thoracic society standards of care committee pulmonary embolism guideline development group (2003) British thoracic society guidelines for the management of suspected acute pulmonary embolism. Thorax 58(6): 470-84. 